\title{
EFFECTS OF LONG-TERM TREATMENT WITH ATORVASTATIN AND ROSUVASTATIN ON ACTIVE AVOIDANCE TEST IN INTACT RATS
}

\section{Maria T. Georgieva- \\ Kotetarova, \\ Ivanka I. Kostadinova, Delian P. Delev}

Department of Pharmacology and Clinical Pharmacology, Faculty of Medicine, Medical University - Plovdiv

\section{Corresponding Author:}

Maria T. Georgieva-Kotetarova

Department of Pharmacology and

Clinical Pharmacology

Faculty of Medicine

Medical University - Plovdiv

15A "Vassil Aprilov" str

Plovdiv

Bulgaria

e-mail: mariatgeorgieva@yahoo.com

Received: January 16, 2013

Revision received: February 26, 2013

Accepted: June 26, 2013

\section{Summary}

Statins are widely used for treatment of hyperlipidemia. They have been shown to possess pleiotropic effects apart from their lipid-lowering activity - anti-inflammatory, immunomodulatory, and neuroprotective. Most studies suggest that statins can protect the brain against damage but it is not clear whether they improve cognitive function in patients without neuropathy. The aim of the present study was to investigate the effect of 3-month treatment with atorvastatin and rosuvastatin on learning and memory processes in rats without brain damage. Wistar rats were treated orally for 90 days with atorvastatin and rosuvastatin at a dose of $10 \mathrm{mg} / \mathrm{kg}$ b.w. in parallel with the vehicle-treated group. After that period, learning ability and memory retention was evaluated using an active avoidance test - automatic reflex conditioner (shuttle box). The learning session was carried out on 5 consecutive days. Memory retention test was performed on day 12. The following behavioral reactions were investigated: conditioned responses (avoidance), unconditioned responses (escapes), and intertrial crossings. We found increased number of conditioned responses in groups, treated with atorvastatin $10 \mathrm{mg} / \mathrm{kg}$ b.w., and with rosuvastatin $10 \mathrm{mg} / \mathrm{kg}$ b.w. during the learning session and on the memory retention test, as compared to the same-day control group. The atorvastatin-treated group showed an increased number of unconditioned responses on days 1 and 2, as compared to the control group. In the group treated with Rosuvastatin there was an increased number of escapes on days 1,2 and 4 , as compared to the vehicle-treated group. Atorvastatin and rosuvastatin at a dose of $10 \mathrm{mg} / \mathrm{kg}$ b.w. improved processes of learning and memory retention after the 3-month treatment.

Key words: active avoidance, learning, memory, statins

\section{Introduction}

During the past decade, data was published on the neuroprotective effect of statins [1]. Clinical trials have reported that statin treatment slows down the development of cognitive decline in Alzheimer patients [2] and reduces the risk of dementia in the elderly $[3,4]$. Experimental studies have demonstrated their beneficial effects on cognitive function in animal models of vascular dementia, 
amnesia and after traumatic brain injury [1, 5]. On the other hand, statin administration is associated with cognitive impairment in patients, and that withdrawal of the drug reduces the risk of impairment $[6,7]$.

The aim of the study was to investigate the effect of a 90-day treatment with atorvastatin and rosuvastatin on the processes of learning and memory in rats without brain damage.

\section{Material and Method}

Inbred normotensive male Wistar rats (mean weight of $180-200 \mathrm{~g}$ ) were used. The animals were kept under standard laboratory conditions (temperature $24 \pm 1.0$, humidity of $45 \%$, light/dark cycle 12/12 hours) and received water and food ad libitum. Our study was approved by the ethic committee of Medical University-Plovdiv and by the Bulgarian Food Safety Agency. The animals were treated orally for 90 days. They were divided into 3 groups $(n=8)$ :

Group I - animals, treated orally with saline (1 $\mathrm{ml} / \mathrm{kg} \mathrm{b.w.)}$;

Group II - animals, treated orally with atorvastatin (10 mg/kg b.w.);

Group III - animals, treated orally with rosuvastatin (10 $\mathrm{mg} / \mathrm{kg}$ b.w.).

We used atorvastatin (Atoris) produced and distributed by KRKA, Slovenia and rosuvastatin (Crestor), manufactured by Astra Zeneca. The dose $10 \mathrm{mg} / \mathrm{kg}$ b.w. used in our study 10 and were based on research concerning the neuroprotective effect of atorvastatin and rosuvastatin [8-10]. None of the animals died during the experiment.

After the 90-day period, cognitive function and memory retention were evaluated, using an active avoidance test.

An automatic reflex conditioner for active avoidance was used - shuttle box (Ugo Basile, Italy). The learning session consisted of five consecutive days. Each day, 30 trials were performed with the following parameters: $6 \mathrm{~s}$ light and buzzer $(670 \mathrm{~Hz}$ and $70 \mathrm{~dB}$, accompanied for the last $3 \mathrm{~s}$ by electric shock on the floor of the chamber $(0.4 \mathrm{~mA})$. Between every trial, there were $12 \mathrm{~s}$ intertrial pauses. A memory retention test was performed 7 days later - on the $12^{\text {th }}$ day. The parameters automatically counted were as follows: number of conditioned responses (avoidances), number of unconditioned responses (escapes) and number of intertrial crossings.

The data obtained were analyzed with statistical software SPSS 17.0. One way ANOVA, independent samples T-test, paired samples T-test were used for statistical analyses. A level of $\mathrm{p}<0.05$ was considered significant.

\section{Results}

In the active avoidance test, the number of conditioned responses of the control group did not differ significantly during the learning session and in the memory retention test, as compared to the first day of the experiment. In the

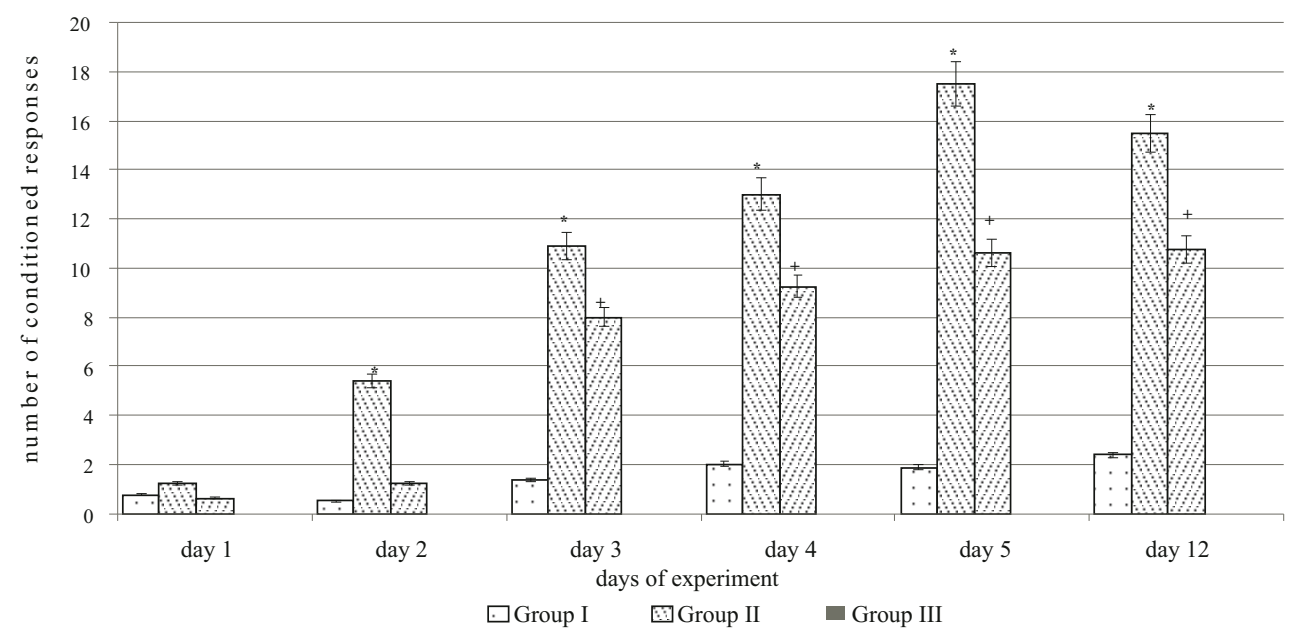

Figure 1. Effect of long-term treatment with atorvastatin and rosuvastatin on the number of conditioned responses in the active avoidance test. Bars represent the mean \pm SEM of 8 animals. Designations: Group I - animals, treated orally with saline $1 \mathrm{ml} / \mathrm{kg}$ b.w.; Group II - animals, treated orally with atorvastatin $10 \mathrm{mg} / \mathrm{kg}$ b.w.; Group III animals, treated orally with rosuvastatin $10 \mathrm{mg} / \mathrm{kg} \mathrm{b.w.;}{ }^{*} \mathrm{p}<0.05$ Group II vs. Group I; $+\mathrm{p}<0.05$ Group III vs. Group I 
group, treated with atorvastatin $(10 \mathrm{mg} / \mathrm{kg}$ b.w.), the number of avoidances increased on days 2, 3, 4 and 5 of the learning session, as well as in the memory retention test on day 12 , as compared to the same-day control group. There was an increase in the number of avoidances on days 3,4 , 5 and 12 of the study in the group, treated with rosuvastatin $(10 \mathrm{mg} / \mathrm{kg}$ b.w.), as compared to the same-day control group (Figure 1).

In the shuttle box active avoidance test, the control group showed no significant difference in the number of unconditioned responses during the experiment, as compared to the first day. When compared to the same day control group, the rats treated with atorvastatin $(10 \mathrm{mg} / \mathrm{kg} \mathrm{b.w.)}$ had increased number of escapes on days 1 and 2 . In the group, treated with rosuvastatin $(10 \mathrm{mg} / \mathrm{kg}$ b.w.), an increased number of escapes was registered on days 1, 2 and 4, as compared to the number of escapes in saline-treated animals on the same days (Figure 2).

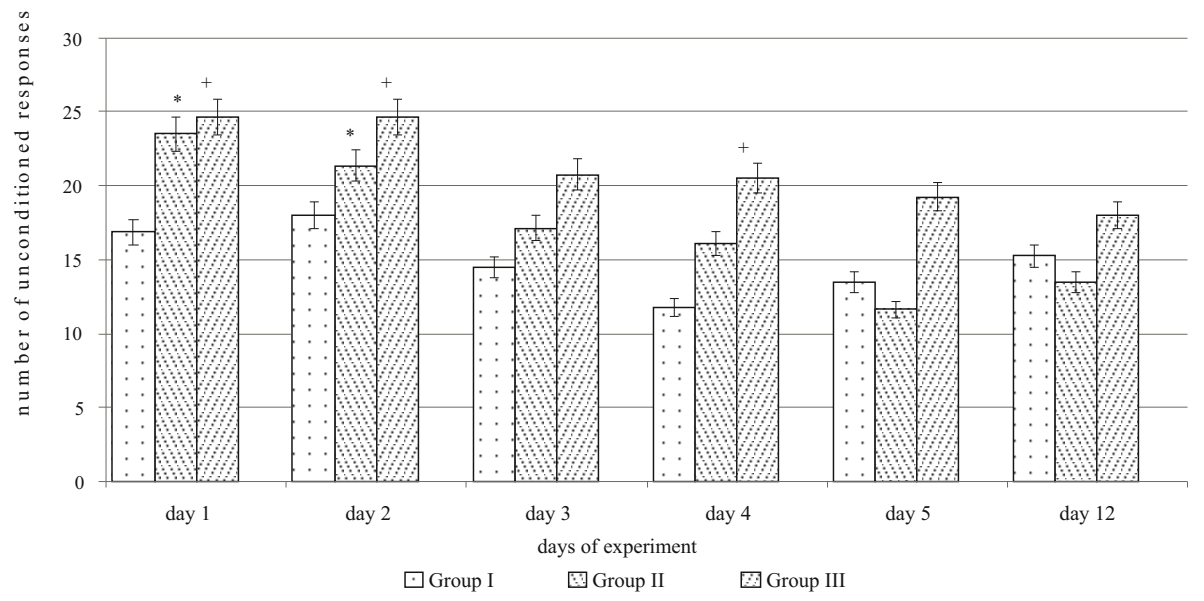

Figure 2. Effect of long-term treatment with atorvastatin and rosuvastatin on the number of unconditioned responses in the active avoidance test. Bars represent the mean \pm SEM of 8 animals. Designations: Group I - animals, treated orally with saline $1 \mathrm{ml} / \mathrm{kg}$ b.w.; Group II - animals, treated orally with atorvastatin $10 \mathrm{mg} / \mathrm{kg}$ b.w.; Group III animals, treated orally with rosuvastatin $10 \mathrm{mg} / \mathrm{kg}$ b.w.; ${ }^{*} \mathrm{p}<0.05$ Group II vs. Group I; $+\mathrm{p}<0.05$ Group III vs. Group I

In the active avoidance test, the animals treated with atorvastatin and rosuvastatin showed no significant differences in the number of intertrial crossing, which allows us to assume that the data regarding the other two parameters was reliable (Figure 3 ).

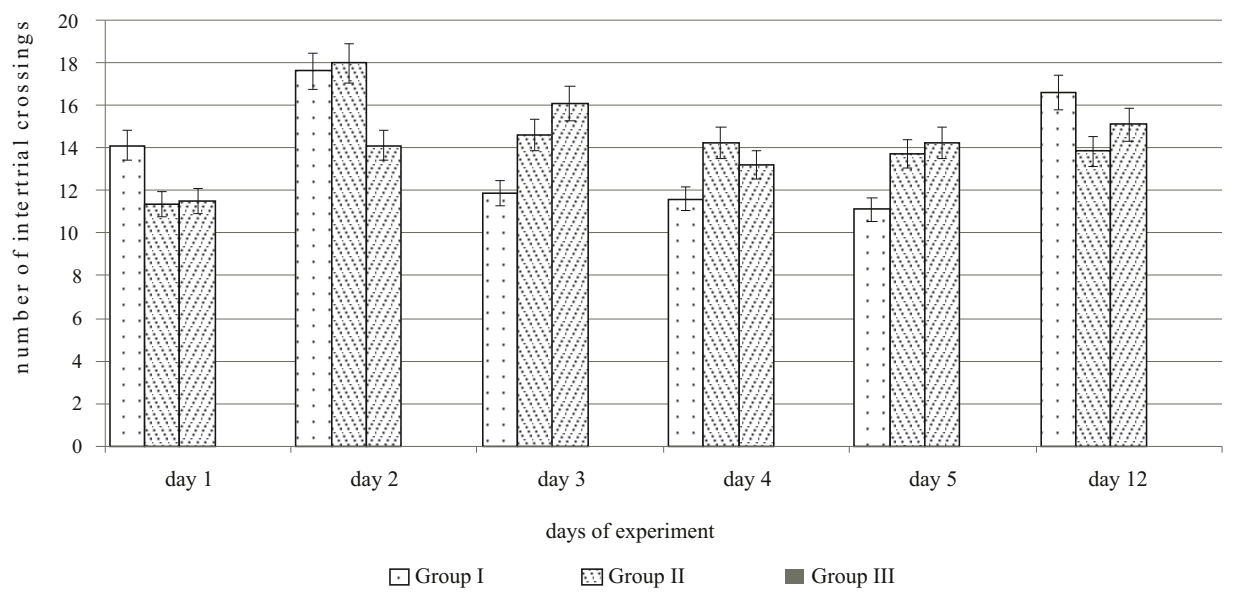

Figure 3. Effect of long-term treatment with atorvastatin and rosuvastatin on the number of intertrial crossings in the active avoidance test. Bars represent the mean \pm SEM of 8 animals. Designations: Group I - animals, treated orally with saline $1 \mathrm{ml} / \mathrm{kg}$ b.w.; Group II - animals, treated orally with atorvastatin $10 \mathrm{mg} / \mathrm{kg}$ b.w.; Group III - animals, treated orally with rosuvastatin $10 \mathrm{mg} / \mathrm{kg} \mathrm{b.w}$ 


\section{Discussion}

In the literature available there is insufficient data concerning the influence of statin-treatment on processes of learning and memory in rats without brain damage. Most studies suggest a beneficial effect of statin treatment on learning and memory performance in animals with neuropathy. However, data from the few studies showed no improvement in statin-treated control animals, as compared to untreated controls. This suggests that statins can protect the brain against damage but it is still uncertain whether they can improve cognitive function in intact animals [1].

Baytan et al. (2008) investigated the effect of 45-day treatment with simvastatin on spatial memory, evaluated with the Barnes maze test. The results showed impairment of spatial memory in animals receiving simvastatin 10 $\mathrm{mg} / \mathrm{kg}$ b.w. [11]. The results from our study differ from those of Baytan et al., as we report improvement of learning performance and longterm memory retention in the active avoidance test. It has been reported, that there is a differences in the effect of simvastatin and fluvastatin on spatial memory. After a 4-week treatment, fluvastatin did not alter spatial memory in rats [12]. The difference in the results from the neuroprotective effect of statin in animals without brain damage could give us the option to choose the most suitable drug preparation in view of the aim of treatment.

Douma et al. (2011) have investigated the influence of simvastatin on cognitive function in olfactory bulbectomized rats, which leads to severe cognitive impairment with deficits in learning and memory. Simvastatin did not improve cognitive performance in the open-field test, step-through passive avoidance test and the

\section{References}

1. van der Most PJ, Dolga A, Nijholt I, Luiten P, Eisel U. Statins: Mechanisms of neuroprotection. Prog Neurobiol. 2009;88(1):64-75.

2. Masse I, Beordet R, Deplanque D, Al K, Richard F, Libersa et al. Lipid lowering drugs are associated with a slower cognitive decline in Alzheimer's disease. J Neurol Neurosurg Psychiatry. 2005; 76(12):1624-9.

3. Jick H, Zornberg GL, Jick S, Seshadri S, Drachman DA. Statins and the risk of dementia, The Lancet. 2000;356:1627-31. object-location task. However, simvastatin improved cognition in intact rats [113]. In our study, the cognitive function of the rats improved, as demonstrated by results from the active avoidance test. Improvement of cognition could be attributed to the modulation of signaling pathways implicated in synaptic plasticity and memory formation [14]. Increased levels of NMDA receptors following chronic treatment with simvastatin have been reported [15]. These receptors play an important role in learning and memory [16]. In the memory formation process, nitric oxide (NO) serves as a retrograde messenger, which modulates synaptic function and affects short and long-term memory [17]. It has been reported that statins increase eNOS expression and inhibit iNOS, which results in increased levels of $\mathrm{NO}$ without leading to overproduction [1]. These factors could be part of the complex mechanism involved in the improvement of cognitive performance by statin treatment.

\section{Conclusion}

The analysis of the influence of long-term oral treatment with statins on learning and memory performance allows us to conclude that atorvastatin $10 \mathrm{mg} / \mathrm{kg}$ b.w. and rosuvastatin 10 $\mathrm{mg} / \mathrm{kg} \mathrm{b.w}$. improve learning performance and long-term memory retention in the active avoidance test.

\section{Acknowledgements}

This work was supported by a grant from Medical University-Plovdiv.

4. Bernick C, Katz R, Smith NL, Rapp S, Bhadelia R, Carlson M, et al. Statins and cognitive function in the elderly: the Cardiovascular Health Study. Neurology. 2005;65(9):1388-94.

5. Parle M, Singh N. Reversal of memory deficits by Atorvastatin and Simvastatin in Rats. Yakugaku Zasshi. 2007;127(7):1125-37.

6. Evans MA, Golomb BA, Statin-associated adverse cognitive effects: survey results from 171 patients. Pharmacotherapy. 2009;29(7):800-11.

7. Padala KP, Padala PR, Potter JF, Simvastatininduced decline in cognition, Ann Pharmacother. 2006;40(10):1880-3. 
8. Kalonia H, Kumar P, Kumar A. Comparative neuroprotective profile of statins in quinolinic acid induced neurotoxicity in rats. Behav Brain Res. 2011;216(1):220-8.

9. Wang H, Lynch JR, Song P, Yang HJ, Yates RB, Mace B, et al. Simvastatin and atorvastatin improve behavioral outcome, reduce hippocampal degeneration and improve cerebral blood flow after experimental traumatic brain injury. Exp Neurol. 2007;206(1): 56-69.

10. Ucak A, Onan B, Guler A, Sahin MA, Kılıçkaya O, Oztaş E, et al. Rosuvastatin, a new generation 3hydroxy-3-methylglutaryl coenzyme a reductase inhibitor, reduces ischemia/reperfesion-induced spinal cord tissue injury in rats. Ann Vasc Surg. 2011;25(5):686-95.

11. Baytan SH, Alkanat M, Okuyan M, Ekinci M, Gedikli E, Ozeren M, et al. Simvastatin impairs spatial memory in rats at a specific dose level. Tohoku J Exp Med. 2008;214(4):341-9.

12. Baytan SH, Alkatan M, Ozeren M, Ekinci M, Akgun A. Fluvastatin alters psychomotor performance and daily activity but not the spatial memory in rats. Tohoku J Exp Med. 2006,209(4), 311-20.

13. Douma TN, Borre Y, Hendriksen H, Olivier B, Oosting RS. Simvastatin improves learning and memory in control but not in olfactory bulbectomized rats. Psychopharmacology. 2011;216(4):537-44.

14. Vaughan CJ. Prevention of stroke and dementia with statins: effects beyond lipid lowering. Am J Cardiol. 2003;91(4A):23B-29B.

15. Wang Q, Zengin A, Deng C, Li Y, Newell KA, Yang GY, et al. High dose of simvastatin induces hyperlocomotive and anxiolytic-like activities: the association with the upregulation of NMDA receptor binding in the rat brain. Exp Neurol. 2009;216(1):132-8.

16. Magnusson KR, Cotman CW. Effects of aging on NMDAnand MK801 binding sites in mice. Brain Res. 1993;604(1-2):334-7.

17. Malenka RC, Nicoll RA. Long-term potentiationa decade of progress? Science 1999; 285(5435): 1870-4. 